\title{
Power Generation on Highway by Harnessing Wind Power
}

\begin{abstract}
This paper is focused on the wind power generated by harnessing the wind power generated by moving vehicles on the roadway. The wind power and solar power is the future of power generation system. The wind power have the least carbon footprint as compare to other form of energy sources. In this paper a system for harnessing roadside wind power is discussed in this system a special type of wind turbine is used for harnessing wind generated by moving vehicles and converted into electrical energy by a generator. The electrical energy is stored in the batteries installed in system and further used when require by converting $D C$ into $A C$ by an inverter. The $A C$ power is used for supplying power to houses, street light and many other electrical loads.
\end{abstract}

Vinay Anand

Keywords: Wind, Wind power, future, wind turbine, generator, battery, inverter, house, street light, roadways, vehicles.

\section{INTRODUCTION}

The wind power is 2nd most available source of energy after solar energy[1], which is available for harnessing. So, this project is designed for harnessing this wind energy generated due the moving vehicle on the roadside which can be harness by using specially designed wind turbine only for this purpose[2], the type of wind turbine is designed is vertical axis wind turbine which is more efficient and easy to design than old savonious design[3][4]. For getting maximum output through wind turbine we twisted the blades of wind turbine in fixed calculated angle by twisting the blade we get maximum power output in low pressure of the wind. The designed wind turbine works in all kind of environment. The designed prototype of wind turbine rotates in both the direction i.e. clockwise and anticlockwise direction. The generated electrical energy by the device will be used to power street lights, toll gate, households, etc.

\section{TECHNOLOGIES USED}

Vertical Axis Wind Turbine: The vertical axis wind turbine is designed for harnessing maximum power, the wind turbine converts the kinetic energy into mechanical energy for generating the rotational motion. The wind turbine designed specification are shown in below given table:

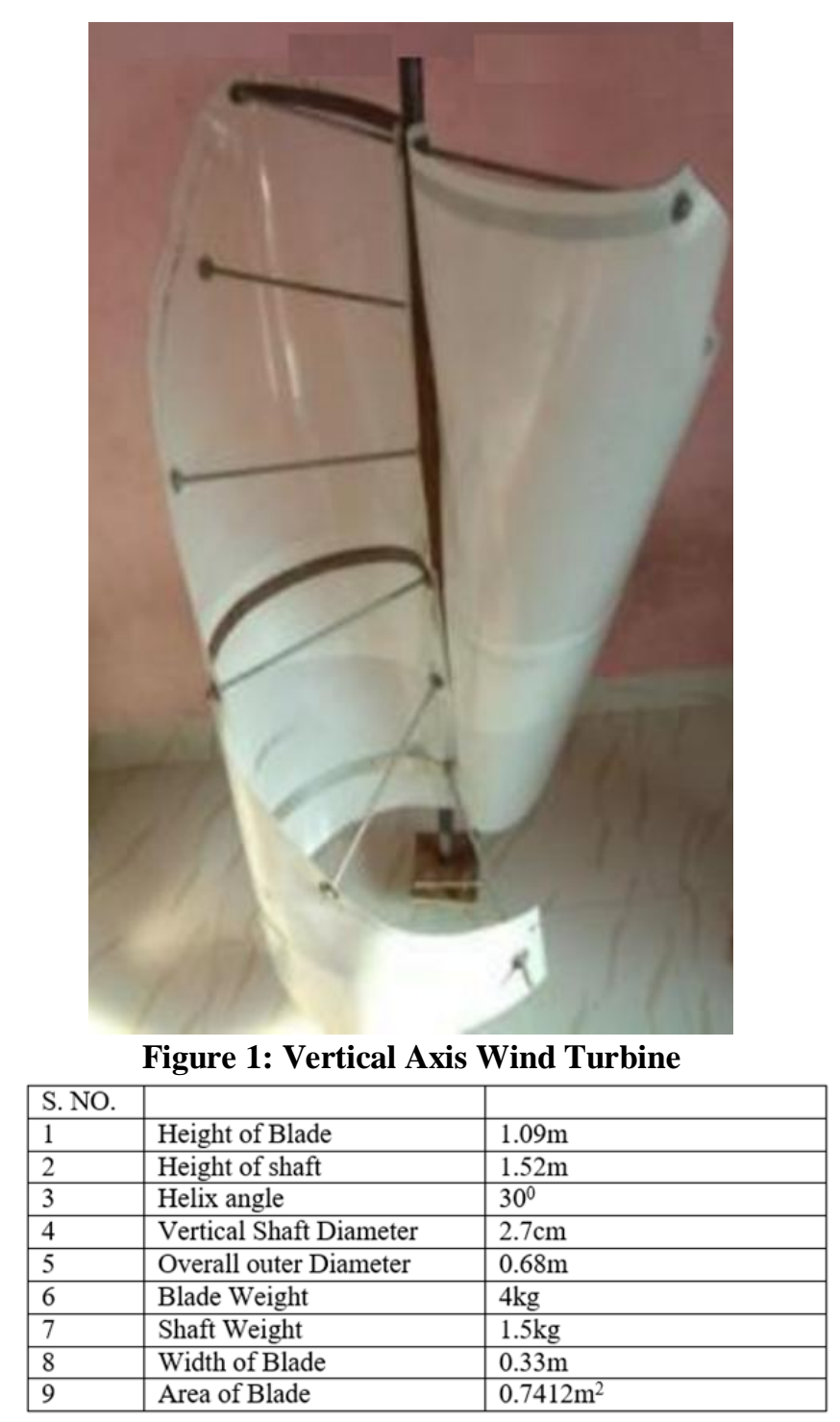

Table 1: Vertical axis Blade specification

Generator: The generator used in system have four stator coil which are connected in series configuration for obtaining desired voltage. The rotor comprising permanent magnets such as neodymium magnet, the shape of all permanent magnets is cuboidal. When rotor rotates in stator it generates EMF in stator coil which results in electrical energy generation[5]. 


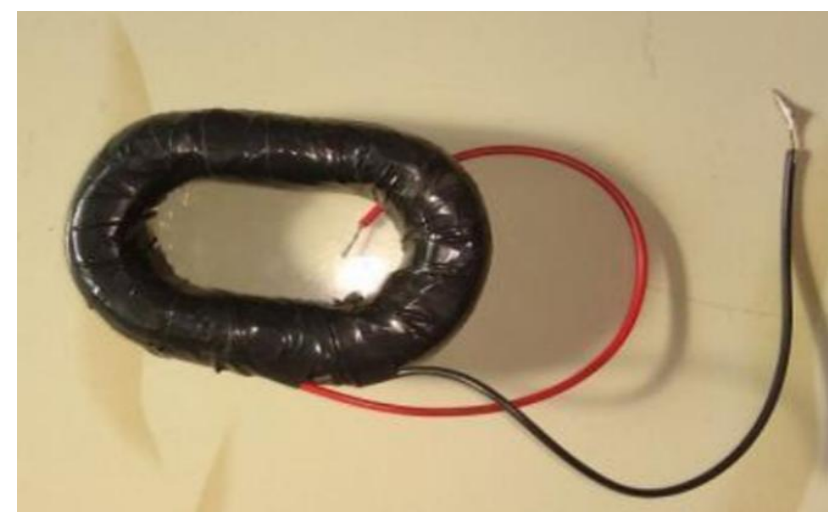

Figure 2: Coil

Battery: Batter is electrochemical device which is used to store electrical energy in the form of chemical and release the electrical energy back when required. The battery installed in system for storing the generated electricity which is not consumed by user or stored for later use[6]. The batteries used in this project are lithium ion battery pack, in which each cell is connected in series and parallel configuration with each other (13s30p). Each cell of pack is of 3.7 volt and 2Ah energy density for storage, it makes the pack of capacity of $2.8 \mathrm{KWh}$ for storing electrical power generated by system[7].

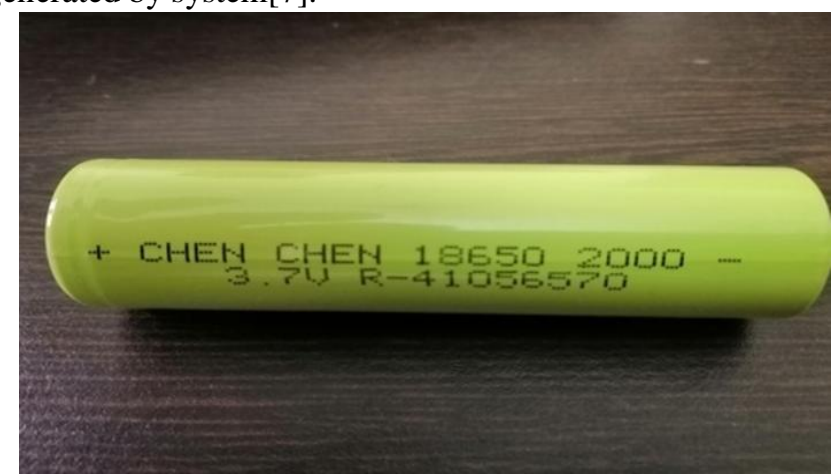

Figure 3: Li-ion cell 3.7V and 2Ah

Li-ion Battery Charger: A li-ion battery charging unit is installed in system for proper charging of li ion cell for safety purpose and increasing the life of battery pack. The liion cell are cells are highly unstable if not handled properly it includes its charging. The cell is over charged for a long time it have high chances of catching fire. So, for removing these possibilities we used li-ion battery charging unit[8].

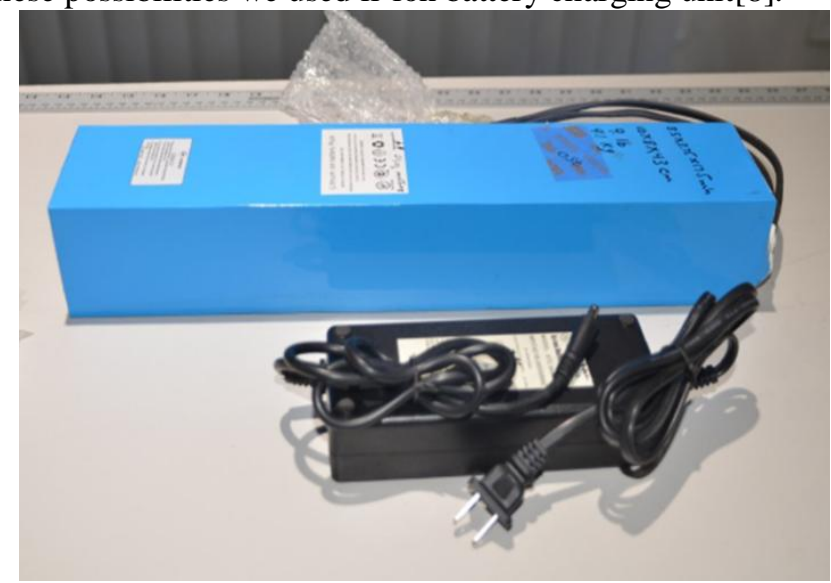

Figure 4: Li-ion Battery pack charging unit
Inverter: An inverter is a device which is used for converting direct current into alternating current. In this project we implemented an inverter for converting 48V DC power into $220 \mathrm{~V}, 50 \mathrm{~Hz}$ AC for supplying power to household loads, street light and many other electrical loads up-to 1500Watt[9].

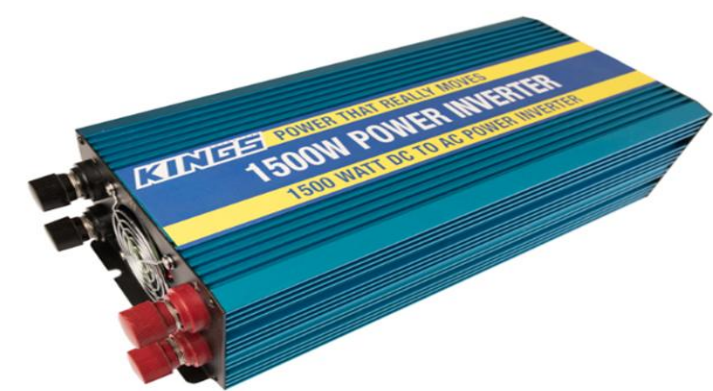

Figure 5: 1500Watt inverter

\section{BLOCK DIAGRAM}

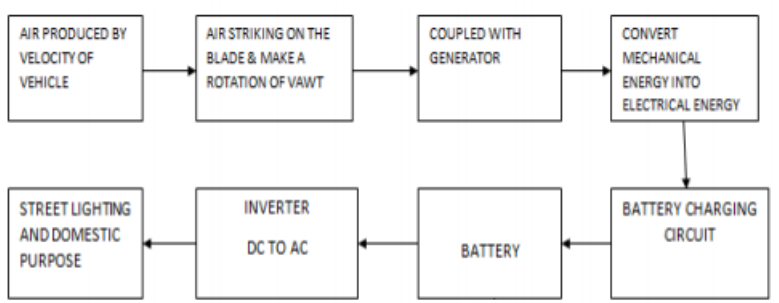

Figure 6: Block Diagram of system working

\section{WORKING OF SYSTEM}

The system works as any wind turbine works it only need continuous flow of wind for this the system is designed for harnessing wind power form the moving vehicle on roadways. When vehicle moves on roadways, they generates wind because of aerodynamic drag the wind moves sideways. Due to generated wind by vehicle our system gets wind power necessary for rotating the wind turbine. The specially designed blades of wind turbine captures the maximum wind for rotating the generated connected with the shaft of blade for creating rotation motion inside. The generator converts mechanical power into electrical power. After that the generated electrical power is sent to battery charging unit for charging the battery optimally. The stored power when need can be used by converting through inverter installed in said system. The electricity which is generated by using this system is used for powering the surrounding houses and street lights mainly. 


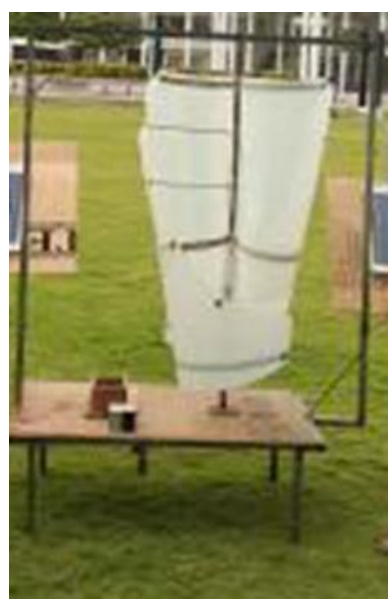

Figure 7: Roadside Wind turbine prototype

\section{RESULT}

The wind turbine is tested in three condition and all the data is recorded:

First condition light traffic: the wind turbine is tested in light traffic area and the system is works as designed to works. The wind turbine is rotated at the speed of $150 \mathrm{RPM}$ with 65 Volt as output.

Second condition Medium Traffic: the wind turbine is placed at medium traffic density area with an average speed of vehicles about $65 \mathrm{kmph}$. The wind turbine blades rotated at speed of 200 RPM with 75.3 Volts output generated during the rotation.

Third condition Heavy Traffic: The wind turbine is placed on Expressway with heavy traffic and average speed of moving vehicle is $83 \mathrm{kmph}$. The wind turbine gain a speed of rotation of 275 RPM and 87 Volt as output of system.

\section{CONCLUSION}

The system is designed and worked as planned by implementing this type of system we can increase the production of renewable energy and improving the condition of our climate by reducing the consumption of fossil fuel. In future the efficiency of system will be improved and the wind power generating system will be used as charging station for electrical vehicles.

\section{REFERENCES}

1. U. Aswathanarayana, "Wind power," in Green Energy: Technology, Economics and Policy, 2010.

2. "Wind turbines," Fluid Mech. its Appl., 2015.

3. P. Nagare, A. Nair, R. Shettigar, P. Kale, and P. Nambiar, "Vertical axis wind turbine," in Proceedings International Conference on Technologies for Sustainable Development, ICTSD 2015, 2015.

4. L. J. Vermeer, J. N. Sørensen, and A. Crespo, "Wind turbine wake aerodynamics," Progress in Aerospace Sciences. 2003.

5. G. Nicoll and M. J. Boss, "Generators," in Electrical Safety: Systems, Sustainability, and Stewardship, 2014.

6. W. D. Hill, "Battery," English J., 2006.

7. J. B. Goodenough and K. S. Park, "The Li-ion rechargeable battery: A perspective," Journal of the American Chemical Society. 2013.

8. Z. Yang et al., "Electrochemical Energy Storage for Green Grid," Chem. Rev., 2011.

9. J. A. Melkebeek, "Inverter," in Power Systems, 2018. 